\title{
Comparing the effect of statins on hepatic fibrosis induced by carbon tetrachloride in Wistar rats
}

\author{
Anupama Dhavaleshwar ${ }^{1}$, Bharti Chogtu ${ }^{1 *}$, Deepak Nayak ${ }^{2}$, Praveen Kumar S. E. ${ }^{1}$
}

\author{
${ }^{1}$ Department of Pharmacology, ${ }^{2}$ Department of Pathology, Kasturba Medical College, Manipal Academy of Higher \\ Education, Manipal, Karnataka, India
}

Received: 28 October 2021

Accepted: 24 November 2021

\author{
*Correspondence: \\ Dr. Bharti Chogtu, \\ Email: krishna@hotmail.com
}

Copyright: (c) the author(s), publisher and licensee Medip Academy. This is an open-access article distributed under the terms of the Creative Commons Attribution Non-Commercial License, which permits unrestricted non-commercial use, distribution, and reproduction in any medium, provided the original work is properly cited.

\begin{abstract}
Background: The clinical studies have shown contrary results regarding hepatoprotective effect of statins. However, antifibrotic properties of statins in in vitro and in vivo experimental models have been demonstrated. The purpose of this study was to assess and compare the effect of statins on serum liver enzymes and their antifibrotic effects.

Methods: Forty two rats were divided into 7 groups (I to VII) $(n=6)$. Liver toxicity was induced by injecting carbon tetrachloride $(1 \mathrm{ml} / \mathrm{kg})$. Control groups received corn oil $(0.1 \mathrm{ml} / 100 \mathrm{gm})$ and carboxy methyl cellulose $(0.50 \%)$ respectively. Group III to VII received carbon tetrachloride $\left(\mathrm{CCl}_{4}\right)$ for 6 weeks and then groups IV, V, VI and VII received simvastatin $(10 \mathrm{mg} / \mathrm{kg})$, atorvastatin $(15 \mathrm{mg} / \mathrm{kg})$, rosuvastatin $(2 \mathrm{mg} / \mathrm{kg})$ and silymarin $(50 \mathrm{mg} / \mathrm{kg})$ for another 8 weeks respectively. Serum aspartate aminotransferase (AST), alanine aminotransferase (ALT) and alkaline phosphatase (ALP) levels were estimated in all the groups at baseline, 6 weeks and 14 weeks. At 14 weeks, histopathology of liver was done in all groups.

Results: At 14 weeks, all the test groups (IV, V and VI) showed a significant decrease in serum ALT, AST and ALP levels as compared to control $(\mathrm{p}<0.05)$ and group III $(\mathrm{p}<0.05)$. On intergroup comparison, liver enzymes in rats in group VI (rosuvastatin) and group V (atorvastatin) were decreased more in comparison to group IV (simvastatin) but the difference was not statistically significant except for AST levels where the difference was significant between the statins. There was decrease in hepatic fibrosis by statins with rosuvastatin being superior followed by atorvastatin and simvastatin.

Conclusions: In the present study statins decreased the serum AST, ALT and ALP levels and histopathological changes were reversed by statins in $\mathrm{CCl}_{4}$ induced hepatotoxic models.
\end{abstract}

Keywords: Statins, Hepatotoxicity, Carbon tetrachloride, Hepatic fibrosis

\section{INTRODUCTION}

Liver diseases are considered as a public health disease because of underway epidemics of obesity and diabetes. The range of liver diseases varies from simple steatosis, hepatosteatosis, liver fibrosis (non-alcoholic fatty liver disease, liver cirrhosis) and finally hepatic cellular carcinoma. ${ }^{1}$ Hepatic fibrosis, a reversible wound healing process, is a result of chronic non resolving inflammation. Carbon tetrachloride $\left(\mathrm{CCl}_{4}\right)$ by altering the permeability of plasma lysosomal and mitochondrial membranes impairs the functioning of hepatocytes and causes chronic liver injury. Also generation of highly reactive metabolites of free radicals in plasma leads to centrizonal necrosis in hepatocytes. $^{2}$

Statins are specific inhibitors of the 3-hydroxyl-3-methylglutaryl-coenzyme A (HMG-CoA) reductase which is a rate limiting enzyme in cholesterol biosynthesis, and are primary agents used in the treatment of hyperlipidemia. The number of patients taking statins is increasing world over and American College of Cardiology has extended 
the indication of statins for prevention of cardiovascular diseases. Statins have pleiotropic properties such as antiinflammatory, anti-proliferative, antithrombotic, anticancer and immunomodulatory in vivo and vitro in addition to cholesterol lowering effects. Statins also reduce the triglycerides level in liver and ameliorate sever hepatic steatosis thereby improving the fibrogenesis. ${ }^{2}$ A recent systematic review and meta-analysis has concluded that statins attenuate the progression of hepatic fibrosis. Statins have a role in the prevention of hepatic decompensation in patients with cirrhosis and can decrease all-cause mortality in chronic liver disease. ${ }^{3}$ The status of statins in patients with hepatic fibrosis is conflicting and researchers are of the opinion that further studies are required to elucidate the effect of statins in patients with hepatic fibrosis.

With this background, the present study aimed at evaluating and comparing the effect of statins on liver enzymes and their antifibrotic properties.

\section{METHODS}

The animal care and experiments conducted in this study were in accordance with committee for the purpose of control and supervision of experiments on animals (CPSCEA) guidelines for handling and care of animals. The study was initiated after obtaining clearance from institutional animal ethics committee (IAEC/KMC/89/2016), Kasturba Medical College, Manipal Academy of Higher Education.

\section{Drugs/reagents}

Corn oil, $\mathrm{CCl}_{4}$, silymarin (50 $\mathrm{mg} / \mathrm{kg}$ ), carboxymethyl cellulose (CMC) $0.5 \%$, atorvastatin (15 $\mathrm{mg} / \mathrm{kg})$, rosuvastatin $(2 \mathrm{mg} / \mathrm{kg})$, simvastatin $(10 \mathrm{mg} / \mathrm{kg})$ and fluvastatin $(10 \mathrm{mg} / \mathrm{kg})$. Serum aspartate aminotransferase
(AST), alanine aminotransferase (ALT) and alkaline phosphatase (ALP) kits were obtained from Hitech Biomedicals, Mangalore. The animals were divided into 7 groups as shown in Table 1.

Baseline serum AST, ALT and ALP levels were estimated in all the groups (group I to group VII). Then liver fibrosis was then induced by injecting $\mathrm{CCl}_{4}$ to 30 rats (group III, IV, V, VI and VII) at a dose of $1 \mathrm{ml} / \mathrm{kg}, 1: 1$ mixture with corn oil, intraperitoneally twice weekly for 6 weeks. ${ }^{4}$ Induction of liver fibrosis was assessed by the biochemical estimation. Biochemical estimation was done at 6 weeks to check for increase in the liver enzymes i.e. serum AST, ALT and ALP. Group I of rats $(n=6)$ were injected intraperitoneally corn oil $0.1 \mathrm{ml} / 100 \mathrm{gm}$ twice a week for 6 weeks (vehicle) and served as a negative control group. Group II of rats were given orally normal saline daily for 6 weeks and served as control.

After 6 weeks, biochemical estimation (serum AST, ALT and ALP) was done in all groups, followed by administration of the following compounds.

Group I and III were administered saline, group II was administered CMC; group IV was administered simvastatin and $\mathrm{CMC}$; group $\mathrm{V}$ was administered atorvastatin and $\mathrm{CMC}$; group VI was administered rosuvastatin and CMC; and group VII was administered silymarin. These drugs were administrated for 8 weeks.

At the end of $(8+6) 14$ weeks the blood samples were collected for estimation of serum AST, ALT and ALP. The blood samples were centrifuged at the rate of 3000 revolutions per minute (rpm) for 15 mins to separate serum, which was used to measure the levels of ALT, AST and ALP by using Semi Auto Analyser and expressed in $\mathrm{U} / 1$.

Table 1: Grouping of animals for the study.

\begin{tabular}{|llll|}
\hline Groups $(\mathbf{n = 6})$ & Drugs & Dose & Duration \\
\hline Group I & Corn oil & $0.1 \mathrm{ml} / 100 \mathrm{gm}^{4}$ & Twice a week for 6 weeks \\
\hline Group II & CMC & $0.50 \%{ }^{5}$ & 8 weeks (after 6 weeks) \\
\hline Group III & Corn oil + CCl4 & $0.1 \mathrm{ml} / 100 \mathrm{gm}+1 \mathrm{ml} / \mathrm{kg}^{4}$ & Twice a week for 6 weeks \\
\hline Group IV & Simvastatin+CMC & $101 \mathrm{mixture}$ of CCl4 and corn oil] & \\
\hline Group V & Atorvastatin+CMC & $15 \mathrm{mg} / \mathrm{kg}^{7}$ & 8 weeks (after 6 weeks) \\
\hline Group VI & Rosuvastatin+CMC & $2 \mathrm{mg} / \mathrm{kg}^{8}$ & 8 weeks (after 6 weeks) \\
\hline Group VII & Silymarin & $50 \mathrm{mg} / \mathrm{kg}^{9}$ & 8 weeks (after 6 weeks) \\
\hline
\end{tabular}

After twenty-four hours of last drug dosing, each animal was weighed and then sacrificed by cervical dislocation. Liver, removed by dissection, was washed with the physiological solution and dried. The tissues were fixed in $10 \%$ formalin and embedded in paraffin wax. Sections of the tissues were stained by hematoxylin and eosin (H\&E) stain and seen under microscope for histological changes.

\section{Statistical analysis}

Data analysis was performed using statistical package for the social sciences (SPSS) version 17.0 and excel software. For baseline values, descriptive analysis was done. The results were expressed as mean \pm standard error of mean (SEM). To compare the levels of serum AST, ALT and 
ALP between the different groups analysis of variance (ANOVA) followed by post hoc Tuckey's test was used. For comparing the histological scoring in different groups Pearson's-Chi square test was used. $\mathrm{P}$ value $<0.05$ was taken as significant.

\section{RESULTS}

Serum AST, ALT and ALP levels were estimated at baseline, six weeks and 14 weeks.

\section{AST}

The values of AST in different groups shown in Table 2. A significant increase in AST values is seen in group III as compared to group I $(\mathrm{p}=0.013)$ at 6 weeks. Group IV, V, VI and VII also show a significant increase $(p<0.05)$ compared to control group I. At 14 weeks, there is an increase in AST value in group IV as compared to group I $(p<0.001)$, group II $(p=0.002)$. On comparing group IV with group III and group V there is no statistically significant difference $(\mathrm{p}>0.05)$.

However a significant increase in AST values is seen in group IV as compared to group VI $(\mathrm{p}=0.001)$ and group VII $(\mathrm{p}<0.001)$.

Table 2: The values of AST (U/I) in different groups at baseline, 6 weeks and 14 weeks.

\begin{tabular}{|llll|} 
Groups & $\begin{array}{l}\text { Baseline } \\
\text { (0 week) }\end{array}$ & 6 weeks & 14 weeks \\
\hline I & $74.50 \pm 8.26$ & $76.83 \pm 6.01$ & $78.50 \pm 6.03$ \\
\hline II & $91.16 \pm 2.54$ & $91.16 \pm 2.54$ & $91.16 \pm 2.54$ \\
\hline III & $65.66 \pm 18.45$ & $144.0 \pm 19.01^{*}$ & $144.0 \pm 19.01$ \\
\hline IV & $68.50 \pm 11.60$ & $140.67 \pm 18.43^{*}$ & $197.5 \pm 19.05^{* a}$ \\
\hline V & $93.66 \pm 11.61$ & $163.17 \pm 12.62^{*}$ & $129.6 \pm 32.65$ \\
\hline VI & $57.83 \pm 6.49$ & $172.66 \pm 11.92^{*}$ & $81.83 \pm 14.62^{\mathbf{b}}$ \\
\hline VII & $51.66 \pm 10.81$ & $187.5 \pm 11.23^{*}$ & $59.33 \pm 7.73^{\mathbf{b}}$ \\
\hline
\end{tabular}

The values are mean \pm SEM; $* \mathrm{p}<0.05$ as compared to control (group I and group II) at 6 weeks; ${ }^{*} \mathrm{p}<0.005$ as compared to group II at 14 weeks; ${ }^{a} \mathrm{p}<0.001$ as compared to group I at 14 weeks; ${ }^{\mathrm{b}} \mathrm{p}<0.001$ as compared to group IV at 14 weeks

\section{$A L T$}

The values of serum ALT in different groups is shown in Table 3. At 6 weeks, a significant increase in ALT values is seen in Group V as compared to group I and group II $(\mathrm{p}<0.001)$. Groups III, IV, VI and VII also show an increase in ALT values but the increase is not statistically significant as compared to control groups. After 14 weeks there was a decrease in serum ALT in group IV, V, VI and VII and the decrease was significant in group IV as compared to group I $(\mathrm{p}=0.048)$ and group II $(\mathrm{p}=0.049)$. On intergroup comparison of statins and between statins and silymarin, no significant difference $(p>0.05)$ was observed.
Table 3: The values of ALT (U/l) in different groups at baseline, 6weeks and 14 weeks.

\begin{tabular}{|llll|} 
Groups & $\begin{array}{l}\text { Baseline } \\
\text { (0 week) }\end{array}$ & 6 weeks & 14 weeks \\
\hline I & $62.66 \pm 8.58$ & $97.50 \pm 18.9$ & $122.0 \pm 26.07$ \\
\hline II & $71.83 \pm 7.65$ & $121.83 \pm 25.98$ & $121.83 \pm 25.98$ \\
\hline III & $45.33 \pm 11.00$ & $185.0 \pm 17.32$ & $101.67 \pm 18.55$ \\
\hline IV & $66.66 \pm 12.78$ & $230.0 \pm 2.30$ & $43.16 \pm 11.38 *$ \\
\hline V & $49.66 \pm 11.02$ & $382.0 \pm 71.02 *$ & $55.83 \pm 8.10$ \\
\hline VI & $31.83 \pm 31.83$ & $172.5 \pm 7.57$ & $54.66 \pm 5.35$ \\
\hline VII & $43.00 \pm 5.05$ & $219.8 \pm 19.31$ & $45.16 \pm 16.74$ \\
\hline
\end{tabular}

The values are mean \pm SEM; $* \mathrm{p}<0.001$ as compared to group I and group II at 6 weeks; ${ }^{*} \mathrm{p}<0.05$ as compared to group I and group II at 14 weeks

\section{$A L P$}

The values of serum ALP in different groups shown in Table 4. There is significant difference between group I and group V $(\mathrm{p}=0.04)$ and group I and group VI $(\mathrm{p}<0.001)$ at 6 weeks. Also a significant difference is seen in group $\mathrm{V}(\mathrm{p}=0.017)$ and group VI $(\mathrm{p}<0.001)$ in comparison to group II. At 14 weeks, there is decrease in ALP levels in group IV, V, VI and VII as compared to group III. However the decrease in non-significant in group IV $(\mathrm{p}=0.05)$. On the other hand the decrease at 14 weeks in comparison to group III is significant in group $\mathrm{V}$ ( $\mathrm{p}=0.008)$, group VI ( $\mathrm{p}=0.024)$, and group VII $(\mathrm{p}=0.011)$. Intergroup comparison between statins and silymarin does not show any significant difference $(\mathrm{p}>0.05)$.

Table 4: The values of AST (U/L) in different groups at baseline, 6 weeks and 14 weeks.

\begin{tabular}{|llll|} 
Groups & $\begin{array}{l}\text { Baseline } \\
\text { ( } \mathbf{0} \text { week })\end{array}$ & 6 weeks & 14 weeks \\
\hline I & $86.16 \pm 21.74$ & $91.66 \pm 6.91$ & $70.33 \pm 5.10$ \\
\hline II & $67.50 \pm 17.26$ & $67.50 \pm 17.26$ & $67.50 \pm 17.26$ \\
\hline III & $46.83 \pm 9.68$ & $173.5 \pm 6.78$ & $106.83 \pm 21.68$ \\
\hline IV & $41.83 \pm 3.24$ & $168.1 \pm 6.05$ & $54.00 \pm 11.31$ \\
\hline V & $50.16 \pm 11.97$ & $298.0 \pm 54.06^{*}$ & $41.50 \pm 3.57^{*}$ \\
\hline VI & $73.00 \pm 21.87$ & $392.5 \pm 88.46^{\mathrm{a}}$ & $48.50 \pm 4.89^{*}$ \\
\hline VII & $75.50 \pm 6.71$ & $256.16 \pm 58.37$ & $43.33 \pm 7.40^{*}$ \\
\hline
\end{tabular}

The values are mean \pm SEM; $* \mathrm{p}<0.05$ compared to group I and group II at 6 weeks; ${ }^{\mathrm{a}} \mathrm{p}<0.001$ as compared to group I and group II 6 weeks; ${ }^{*} \mathrm{p}<0.05$ as compared to group III at 14 weeks

\section{Histopathological changes}

Liver histology was done after the administration of statins/silymarin for 8 weeks. The histological changes were categorized as inflammation, fatty changes, necrosis and fibrosis.

Chi-square test was done to compare the histological changes between the groups.

A significant difference $(\mathrm{p}=0.03)$ between the groups was seen regarding inflammation. There was no inflammation 
in group VI and group VII but in group V the inflammation was seen which was similar to that of group III. Group IV, V, VI and VII did not show any fatty changes.

Regarding necrosis a highly significant difference $(p<0.001)$ was seen between the groups. Group IV did not show any necrosis. However group V, VI, VII has shown focal positive necrosis.

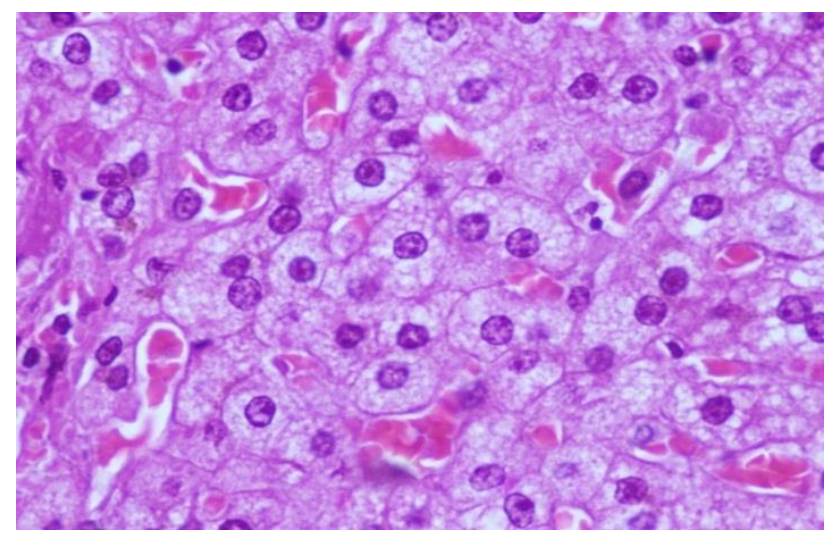

Figure 1: Hepatocytes showing feathery degeneration and early steatosis (H\&E; x400).

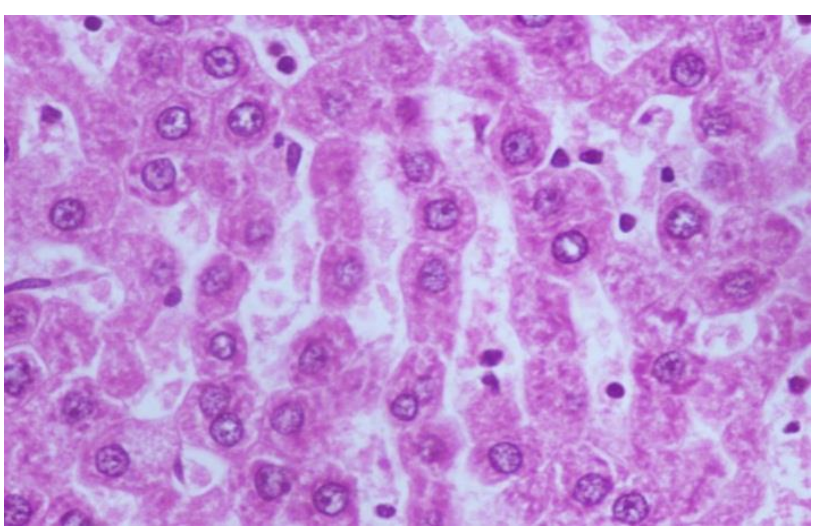

Figure 2: Hepatocytes showing feathery degeneration and granular mitochondrial prominence (H\&E; x400).

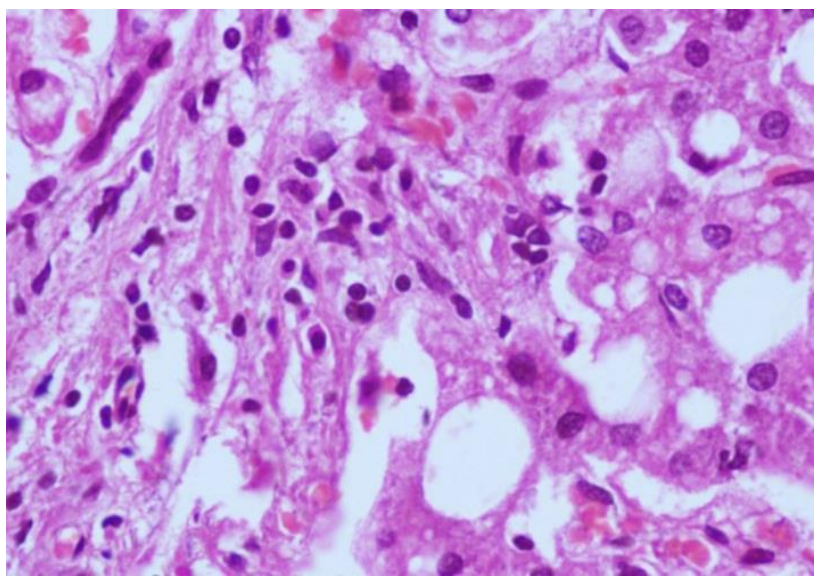

Figure 3: Periportal (zone 1) lymphocytic infiltrates (H\&E; x400).
A highly significant difference $(\mathrm{p}=0.005)$ between the groups was seen on comparing fibrosis. Increased fibrosis is seen in group IV, followed by group $\mathrm{V}$ and then by group VI. $\mathrm{CCl}_{4}$ treated group shows changes in histology in the form of feathery degeneration and early steatosis.as shown in Figure 1. Statin treated groups show histological features like periportal lymphocytes and neutrophils infiltration as shown in Figures 2 and 3.

\section{DISCUSSION}

Some studies reveal statins to have protective effect in hepatic fibrosis, while others did not find any such beneficial effect. The present study was undertaken to evaluate the potential impact of statins on liver functions and hepatic fibrosis using Wistar rats. The study was carried out using liver function tests to evaluate the safety of different statins. Liver fibrosis was induced using $\mathrm{CCl}_{4}$. At 6 weeks there is a significant increase in serum liver enzymes (AST, ALT, and ALP) in the $\mathrm{CCl}_{4}$ treated groups as compared to control groups. The halogenated alkanes $\mathrm{CCl}_{4}$ are used as a hepatotoxic model and produces effects like fatty degeneration, fibrosis and even hepatocellular death. ${ }^{10}$ When liver is exposed to $\mathrm{CCl}_{4}$, various biological processes are mobilized like peroxisome proliferatoractivated receptors (PPAR) signalling pathway, glycerolipid metabolism, arachidonic acid metabolism. This is achieved by regulating targets like ALDH2, and CYP3A4. ${ }^{11}$

At 14 weeks, rosuvastatin and silymarin decreased the AST levels significantly as compared to simvastatin group. Simvastatin treated group showed an increase in the levels of AST. On the contrary, in bile duct ligated mice administration of simvastatin $(0.2 \mathrm{mg} / \mathrm{kg})$ decreased ALT by $87 \%$ and AST by $83 \% .{ }^{12}$ Prophylactic administration of simvastatin prevents LPS induced endothelial dysfunction and inflammation. Thus simvastain has shown to possess hepatoprotective action. ${ }^{13}$

At 14 weeks simvastatin, atorvastatin, rosuvastatin and silymarin treated groups showed a decrease in serum ALT levels but a significant decrease was seen in simvastatin group. However the difference between the ALT levels in different statins and silymarin group was not statistically significant. A systematic review showed that statins may improve serum aminotransferase levels in addition to ultrasound finding. ${ }^{14}$ More studies are required before it could be considered as a treatment for the same. ${ }^{14}$

ALP levels at 14 weeks are reduced in simvastatin, atorvastatin, rosuvastatin and silymarin group. Though the decrease is significant in all the groups, there is a nonsignificant decrease in simvastatin group. Studies show that statin treatment may improve liver enzyme levels as well as hepatic steatosis. ${ }^{15}$ Post-marketing studies have shown that atorvastatin is mostly associated with cholestasis liver injury whereas hepatocellular injury is more common with simvastatin. ${ }^{16}$ However, in a metaanalysis of randomized, placebo-controlled trials it was 
found that statins used for the treatment of hyperlipidemia or for primary or secondary prevention of cardiovascular disease in total of 49,275 patients from 13 trials supported previous observations that pravastatin, lovastatin, and simvastatin, at low-to-moderate doses, are not associated with a significant risk of derangement of liver function test (LFT). ${ }^{17}$

In studies done in obese animals with steatosis or nonalcoholic steatohepatitis, statins have shown to provide hepatic protection (70-90\%) against ischemia-reperfusion injury. ${ }^{18}$ The histological changes found in the liver of rats treated with $\mathrm{CCl}_{4}$ include loss of normal hepatocytes, deposition of collagen and formation of fibre segments. ${ }^{11}$ The changes in liver hepatocytes was seen after 6 weeks of administration of $\mathrm{CCl}_{4}$. In the present study, rats in statin groups have shown less change in liver histology in terms of inflammation, fatty changes, necrosis and fibrosis. The liver histology in $\mathrm{CCl}_{4}$ group showed changes in the form of feathery degeneration, deposition of hemosiderin pigment, sinusoidal dilation, hepatic steatosis, drop-out necrosis. Focal positive necrosis and feathery degeneration was seen in silymarin treated group. Statin treated groups show histological features like periportal lymphocytes and neutrophils infiltration. Statins have an inhibitory effect on proinflammatory cytokine production, like tumor necrosis factor- $\alpha$, IFN- $\gamma$, interleukins like (IL)-1 $\beta$, and IL-6. By reducing neutrophil influx, they attenuate the events, such as macrophage influx, lymphocyte activation, cytokine release and thus prevent inflammation. ${ }^{19}$

By decreasing inflammatory mediators and increasing the anti-inflammatory mediators, statins attenuate the effect of hepatotoxic agents. The effect of atorvastatin $(5 \mathrm{mg} / \mathrm{kg})$ was examined in pathogenic liver effects induced by angiotensin II in male Wistar rats. Angiotensin II produced oxidative stress, hepatic stellate cells (HSC) activation, infiltration of inflammatory cells. Atorvastatin attenuated these effects and thus can have beneficial effects in hepatic inflammation induced by different agents. ${ }^{20}$

Statins can thus have beneficial effects in hepatic dysfunction/fibrosis induced by different hepatotoxic agents. All statins lowered the liver enzymes except simvastatin which increased the AST levels. While comparing the effect of statins on hepatic fibrosis, rosuvastatin seemed to be superior to atorvastatin and simvastatin.

\section{CONCLUSION}

The current study demonstrated that statins normalizes the liver enzyme levels i.e. serum AST, ALT and ALP in $\mathrm{CCl}_{4}$ induced hepatotoxic model. On comparison between the statins, rosuvastatin and Aatorvastatin are superior to Simvastatin though the difference is not statically significant except for AST levels. Fibrosis is prevented by statins in $\mathrm{CCl}_{4}$ induced hepatotoxic models with rosuvastatin being superior followed by atorvastatin and then simvastatin.
Funding: No funding sources

Conflict of interest: None declared

Ethical approval: The study was approved by the Institutional Ethics Committee

\section{REFERENCES}

1. Chong LW, Hsu YC, Lee TF, Lin Y, Chiu YT, Yang $\mathrm{KC}$, et al. Fluvastatin attenuates hepatic steatosisinduced fibrogenesis in rats through inhibiting paracrine effect of hepatocyte on hepatic stellate cells. BMC Gastroenterol. 2015;15:22.

2. Fujii T, Fuchs BC, Yamada S, Lauwers GY, Kulu Y, Goodwin JM, et al. Mouse model of carbon tetrachloride induced liver fibrosis: Histopathological changes and expression of CD133 and epidermal growth factor. BMC Gastroenterol. 2010;10:79.

3. Kamal S, Khan MA, Seth A, Cholankeril G, Gupta D, Singh U, et al. Beneficial effects of statins on the rates of hepatic fibrosis, hepatic decompensation, and mortality in chronic liver disease: a systematic review and meta-analysis. Am J Gastroenterol. 2017;112(10):1495-505.

4. El-Demerdash E, Abdel-Sattar SA, El-Bakly WM, Mohamed EA. Antifibrotic effects of Carvedilol and impact of liver librosis on Carvedilol pharmacokinetics in a rat model. Eur J Drug Metab Pharmacokinet. 2017;42(5):767-79.

5. Mirhadi K. Effect of Intraperitoneally Injection of Different Doses of Lovastatin on Pain and Inflammatory Response Induced by Formalin in Mice. Am J Animal Vet Sci. 2011;6(4):160-5.

6. Motawi TM, Atta HM, Sadik NA, Azzam M. The therapeutic effects of bone marrow-derived mesenchymal stem cells and Simvastatin in a rat model of liver fibrosis. Cell Biochem Biophys. 2014;68(1):111-25.

7. Klein S, Klo J, Schierwagen R, Rner K, Granzow M, Huss S, et al. Atorvastatin inhibits proliferation and apoptosis, but induces senescence in hepatic myofibroblasts and thereby attenuates heaptic fibrosis in rats. Lab Invest. 2012;92(10):1440-50.

8. Okada Y, Yamaguchi K, Nakajima T, Nishikawa T, Jo M, Mitsumoto Y, et al. Rosuvastatin ameliorates high fat and high cholesterol diet induced non-alcoholic steatohepatitis in rats. Liver International. 2013;33:301-11.

9. Salama SM, Abdulla MA, AlRashdi AS, Hadi AH. Mechanism of hepatoprotective effect of Boesenbergia rotunda in Thioacetamide-induced liver damage in rats. Evidence-based Complement Alternat Med. 2013;157456.

10. Weber LW, Boll M, Stampfl A. Hepatotoxicity and mechanism of action of haloalkanes: carbon tetrachloride as a toxicological model. Crit Rev Toxicol. 2003;33(2):105-36.

11. Dong S, Chen Q-L, Song Y-N, Sun Y, Wei B, Li X-Y, et al. Mechanisms of CCl4-induced liver fibrosis with combined transcriptomic and proteomic analysis. $\mathrm{J}$ Toxicol Sci. 2016;41(4):561-72. 
12. Dold S, Laschke M, Lavasani S, Menger M, Jeppsson B, Thorlacius H. Simvastatin protects against cholestasis-induced liver injury. $\mathrm{Br} \mathrm{J}$ Pharmacol. 2009;156(3):466-74.

13. La Mura V, Pasarín M, Meireles CZ, Miquel R, Rodríguez-Vilarrupla A, Hide D, et al. Effects of Simvastatin administration on rodents with lipopolysaccharide-induced liver microvascular dysfunction. Hepatology. 2013;57(3):1172-81.

14. Eslami L, Merat S, Malekzadeh R, NasseriMoghaddam S, Aramin H. Statins for non-alcoholic fatty liver disease and non-alcoholic steatohepatitis. Cochrane Database Syst Rev. 2013;(12):CD008623.

15. Hyogo H, Tazuma S, Arihiro $K$, Iwamoto $K$, Nabeshima Y, Inoue M, et al. Efficacy of atorvastatin for the treatment of non-alcoholic steatohepatitis with dyslipidemia. Metabolism. 2008;57(12):1711-8.

16. Björnsson E, Jacobsen EL, Kalaitzakis E. Hepatotoxicity associated with statins: reports of idiosyncratic liver injury post-marketing. J Hepatol. 2012;56(2):374-80.

17. de Denus S, Spinler SA, Miller K, Peterson AM. Statins and liver toxicity: a meta-analysis. Pharmacotherapy. 2004;24(5):584-91.
18. Ajamieh H, Farrell G, Wong HJ, Yu J, Chu E, Chen J, et al. Atorvastatin protects obese mice against hepatic ischemia-reperfusion injury by Toll-like receptor-4 suppression and endothelial nitric oxide synthase activation. J Gastroenterol Hepatol. 2012;27(8):135361.

19. Maher BM, Dhonnchu TN, Burke JP, Soo A, Wood AE, Watson RW. Statins alter neutrophil migration by modulating cellular Rho activity - a potential mechanism for statins-mediated pleiotropic effects. J Leukoc Biol. 2009;85:186-93.

20. Moreno M, Ramalho LN, Sancho-Bru P, Ruiz-Ortega M, Ramalho F, Abraldes JG, et al. Atorvastatin attenuates angiotensin II-induced inflammatory actions in the liver. Am J Physiol Gastrointest Liver Physiol. 2009;296(2):147-56.

Cite this article as: Dhavaleshwar A, Chogtu B, Nayak D, Kumar SEP. Comparing the effect of statins on hepatic fibrosis induced by carbon tetrachloride in Wistar rats. Int J Basic Clin Pharmacol 2022;11:35-40. 